\title{
Erratum
}

\section{A Model for the Transient Behavior of Tractive Rolling Contacts}

\author{
Farid AI-Bender and Kris De Moerlooze \\ Department of Mechanical Engineering, Division Production Engineering, Machine design and Automation, \\ Katholieke Universiteit Leuven, Celestijnenlaan 300B, E-3001 Heverlee, Belgium \\ Correspondence should be addressed to Farid Al-Bender, farid.al-bender@mech.kuleuven.be \\ Received 7 October 2008; Accepted 19 October 2008
}

Copyright (C) 2008 F. Al-Bender and K. De Moerlooze. This is an open access article distributed under the Creative Commons Attribution License, which permits unrestricted use, distribution, and reproduction in any medium, provided the original work is properly cited.

(1) In [1, equation (35), page 6],

$$
\left(p_{x}, p_{y}\right)=L(u, v)
$$

should be replaced by

$$
\left(p_{x}, p_{y}\right)=\frac{1}{L}(u, v)
$$

(2) In [1, equation (36), page 7],

$$
(u, v)_{\text {new }}=\frac{\mu p_{z}}{L}\left(\frac{(u, v)}{\|(u, v)\|}\right)_{\text {old }}
$$

should be replaced by

$$
(u, v)_{\text {new }}=\mu p_{z} L\left(\frac{(u, v)}{\|(u, v)\|}\right)_{\text {old }} .
$$

\section{REFERENCES}

[1] Farid Al-Bender and Kris De Moerlooze, "A model of the transient behavior of tractive rolling contacts," Advances in Tribology, vol. 2008, Article ID 214894, 17 pages, 2008. 

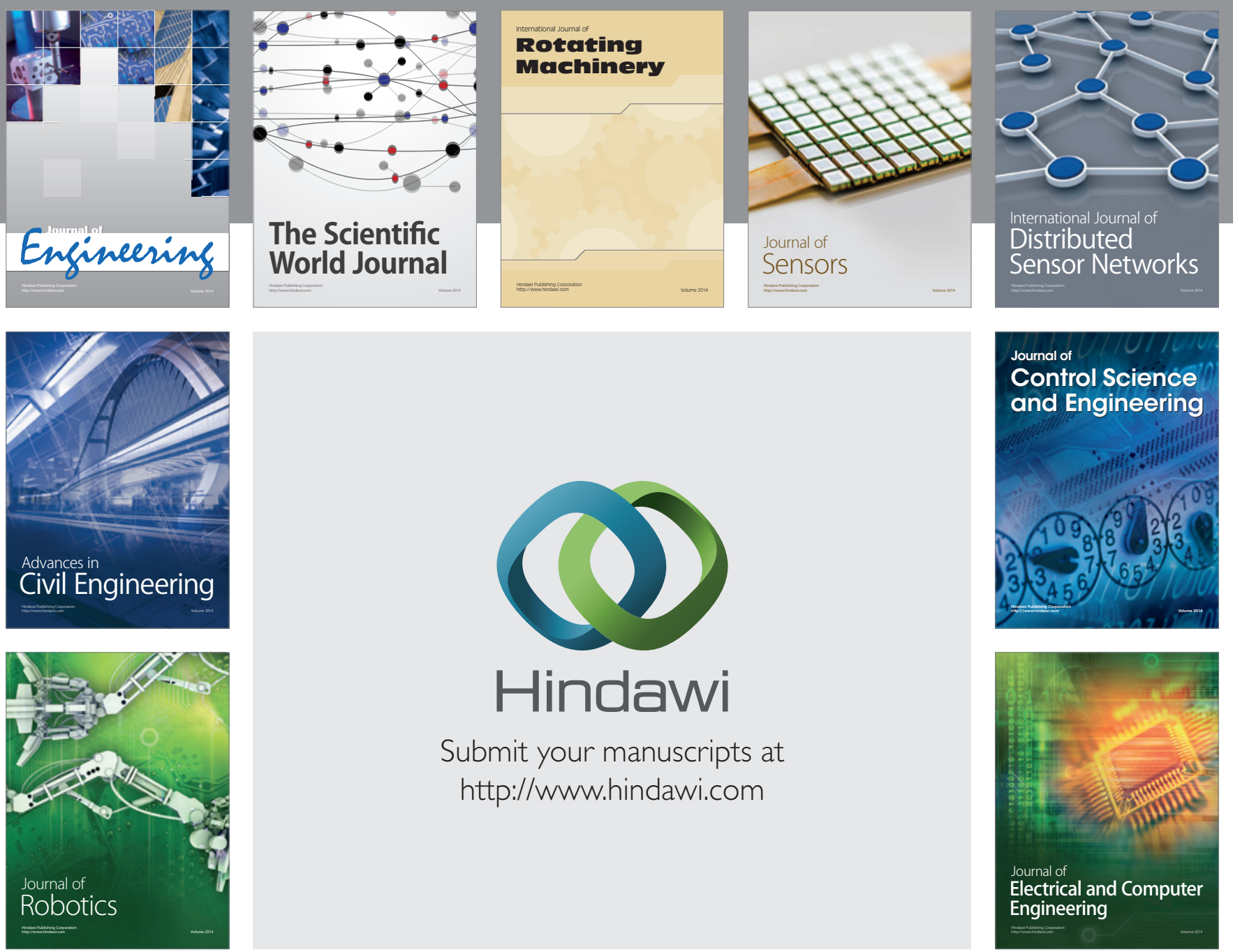

Submit your manuscripts at

http://www.hindawi.com
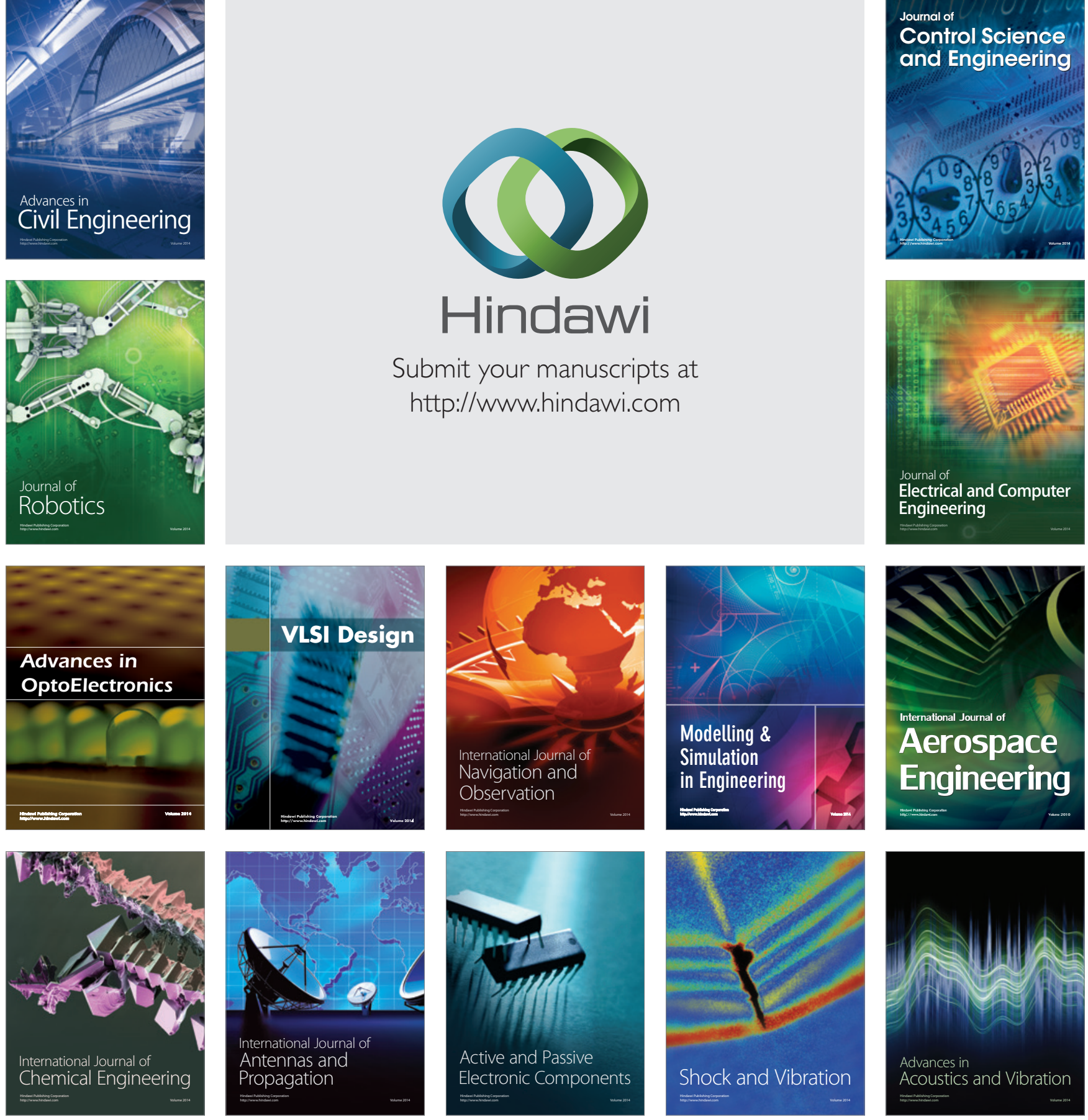